\title{
Williams-Beuren Syndrome: A Case Confirmed by Array-CGH Method
}

\author{
MinYan Jiang ${ }^{1, *} ;$ Li Liu $^{1}$ \\ ${ }^{1}$ Department of Endocrinology and Metabolisms, Guangzhou Women and Children's Medical Center, Guangzhou, China \\ *Corresponding author: MinYan Jiang, Department of Endocrinology and Metabolisms, Guangzhou Women and Children’s Medical Center, Guangzhou, China. E-mail: fdjiang@ \\ hotmail.com
}

Received: October 1, 2014; Accepted: November 14, 2014

Keywords: Williams Syndrome; Aortic Stenosis, Supravalvular

\section{Dear Editor,}

Williams-Beuren Syndrome (WBS) is a rare genetic disorder. The first cases of WBS were described by Williams et al. in 1961 and Beuren et al. in 1962 independently $(1,2)$. Williams reported on a group of children with supravalvular aortic stenosis (SVAS), dysmorphic facies and mental retardation. Beuren presented a similar syndrome with the additional features of peripheral pulmonary stenosis (PPS), dental anomalies and friendly personality. Because of similarity of the facial features and congenital heart defect, it was referred to as Williams-Beuren syndrome. More than $98 \%$ of patients with clinical diagnosis of WBS, have a deletion at chromosome 7q11.23, composed of 28 coding genes, including elastin gene (3). Mutations within the elastin gene have been detected by FISH, which is the standard diagnostic test for WBS. In recent year array-based comparative genomic hybridization (array-CGH) is used for the molecular diagnosis of chromosomal disorders. Array-CGH is available to detect micodeletion/microduplication syndromes and unbalanced chromosomal rearrangements, which is becoming an essential clinical diagnostic tool and is gradually replacing cytogenetic methods. But this technology is not able to indentify balanced chromosomal imbalances such as inversions and translocations. Here we present an 8 month boy with WBS confirmed by array-CGH.

An 8-month-old boy was referred to pediatric respiration department because of recurring pneumonia. Gestational age was 37 weeks and birth weight $2600 \mathrm{~g}$. He is the second child of Healthy, non-consanguineous parents and did not require resuscitation. His elder brother is healthy. At the age of 2 months, the boy suffered growth deficiency. Bodyweight is $4000 \mathrm{~g}$, which was lower than the third centile. At the age of 5 months, his bodyweight was $5000 \mathrm{~g}$. At the age of 6 months, he experienced pneumonia and was admitted to our hospi- tal. During the hospitalization, he presented some facial features such as broad forehead, flat nasal bridge, full cheeks, a wide mouth (Figure 1 ) and a heart murmur. In right upper sternal border, a systolic murmur (2-4/6) with radiation to right cervical region was heard. Doppler echocardiography revealed a mild supra valvular aortic stenosis (SVAS), right pulmonary artery stenosis and patent foramen ovale. After a week of hospitalization, he recovered. At 8 months, he was hospitalized again because of recurring pneumonia and serious malnutrition with delayed mental development. The body weight was $5500 \mathrm{~g}$ and he was unable to hold his head up. According to typical facies, heart defect, growth deficiency, he was suspicious of Williams-Beuren syndrome. The patient was referred for genetic evaluation. Array-CGH was performed, and the result was a 1.4 Mb deletion at chromosome 7q11.23 or arr7q11.23 (72692112$74136663) \times 1$. The diagnosis of WBS was made. In this case, array-CGH has verified a 1.4 Mb deletion at chromosome 7q11.23. According to the genomic basis of the WBS, this deletion is encompassing the telomeric part of WBS region and the commonly deleted genes, including ELN, LIMK1, RFC2 and WBSCR, which is the WBS critical region (4). ELN gene is the best-explored gene, as a major cause of WBS. Its complete lacking may produce the cardiovascular pathology of WBS (5). Deletion of the RFC2 gene may lead to the growth deficiency (6). LIMIK1 gene is important for human cognitive development (7). Genotype-phenotype correlation in our patient corresponds with reference. To conclude, any patient, with multisystem dysmorphy, for example, congenital heart disease, facial malformation, may give a strong hint of WilliamsBeuren's syndrome, and should be investigated by molecular techniques. Array-CGH is an available tool for the rapid and accurate detection of genetic disorders. 


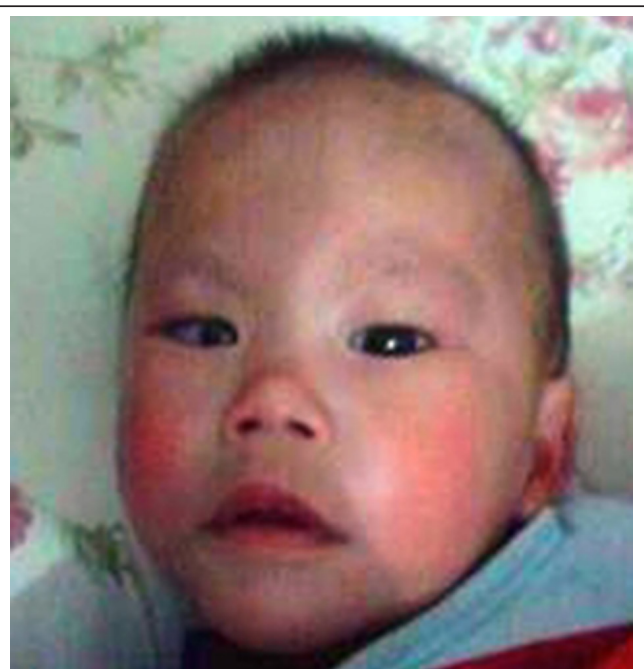

Figure 1. Patient With Craniofacial Features of Williams-Beuren Syndrome

\section{References}

1. Williams JC, Barratt-Boyes BG, Lowe JB. Supravalvular aortic stenosis. Circulation. 1961;24:1311-8.

2. Beuren AJ, Apitz J, Harmjanz D. Supravalvular aortic stenosis in association with mental retardation and a certain facial appearance. Circulation. 1962;26:1235-40.

3. Schubert C. The genomic basis of the Williams-Beuren syndrome. Cell Mol Life Sci. 2009;66(7):1178-97.

4. Dutra RL, Honjo RS, Kulikowski LD, Fonseca FM, Pieri PC, Jehee FS, Bertola DR, Kim CA, et al. Copy number variation in WilliamsBeuren syndrome: suitable diagnostic strategy for developing countries. BMC Res Notes. 2012;5:13.

5. Yau EK, Lo IF, Lam ST. Williams-Beuren syndrome in the Hong Kong Chinese population: retrospective study. Hong Kong Med J. 2004;10(1):22-7.

6. Peoples R, Perez-Jurado L, Wang YK, Kaplan P, Francke U. The gene for replication factor C subunit 2 (RFC2) is within the 7q11.23 Williams syndrome deletion. Am J Hum Genet.1996;58(6):1370-3.

7. Ferrero GB, Biamino E, Sorasio L, Banaudi E, Peruzzi L, Forzano S, di Cantogno LV, Silengo MC, et al. Presenting phenotype and clinical evaluation in a cohort of 22 Williams-Beuren syndrome patients. EurJ Med Genet. 2007;50(5):327-37. 